Tercera Época Año 6. No 11 Julio-Diciembre de 2014

\title{
LA EFICACIA DE UN RÉGIMEN JURÍDICO DE COMBATE A LA CORRUPCIÓN, EN EL MARCO DEL ESTADO CONSTITUCIONAL. UN ABORDAJE EPISTEMOLÓGICO ${ }^{1}$ MARÍA DOLORES ROCHA ONTIVEROS ${ }^{2}$
}

\section{RESUMEN:}

Una de las crecientes preocupaciones de las sociedades contemporáneas es el problema de la corrupción en el contexto de una crisis sistémica que ha debilitado las estructuras del Estado. Su combate debe dimensionarse a partir de dos vertientes: 1. Desde una perspectiva sociocultural y 2. A partir de un diseño institucional, cuyo entramado garantice la eficacia en el sistema social. El propósito de este trabajo es realizar una reflexión y análisis de las ciencias jurídica y política ligadas a principios filosóficos de los objetivos del Estado, a partir de los paradigmas que sustentan el desarrollo de dichas ciencias sociales.

\section{ABSTRACT:}

One of the growing concerns in contemporary societies is the problem of corruption in the context of a systemic crisis that has shaken the structure of the State. The fight must be seen from two tracks: 1 . From the socio-cultural perspective and 2. From an institutional design, that would be the fabric to ensure the effectiveness of the social system. The purpose of this paper is to make a reflection and analysis of the legal sciences and policies linked to philosophies of the objectives of the State, based on paradigms underlying the development of the social sciences.

\section{SUMARIO:}

I. Introducción II. Planteamiento de la cuestión. III. Origen y evolución del concepto Estado.IV.La teoría contractual. V. EI positivismo. VI. Estado de derecho. VII. Diferencias entre el positivismo y el postpositivismo. VIII.EI modelo garantista como una propuesta del postpositivismo. IX Las características de la teoría crítica. X. Las instituciones dentro de un régimen jurídico-político. XI. Reflexión en torno a los cambios en el sistema político. XII. Consideraciones finales.

\section{Palabras Clave: Paradigma, Estado Constitucional, Corrupción Introducción}

La historia político constitucional de nuestro país a partir de la independencia, se desarrolla en ambientes de suma inestabilidad y carencia de una clara visión respecto del modelo institucional que respondiera a los objetivos de una sociedad multicultural y con profundas desigualdades sociales. El siglo XIX en México se inicia con bases constitucionales de influencia extranjera de índole monocultural o mononacional, es decir, los productores de las normas representan a una parte de

\footnotetext{
${ }^{1}$ Ponencia presentada en el III Congreso Iberoamericano y IV Congreso Mexicano de Derecho Administrativo, "Régimen Jurídico de Combate a la Corrupción", Marzo de 2012 cuya temática en este año 2014 particularmente cobra vigencia en nuestro país.

${ }^{2}$ Doctora en Administración Pública, MTC de la Universidad de Sonora
} 
la sociedad, por lo tanto en dichas normas se reflejan los valores de ésta sociedad.

El antecedente de lo anterior sin duda fue el producto de la etapa de la revolución francesa que aunado a la revolución industrial genera efectos políticos, económicos y sociales que cambiaron la concepción del mundo. El Estado de derecho aparece como el Estado moderno democrático, cuyo poder se divide en tres funciones, siendo la legislativa la que sintetiza el pensamiento jurídico. Se concibe a la constitución en un esquema formalista en la que estaba imbuida la teoría del derecho de la época.

En México, en la actualidad, el tema de la corrupción adquiere centralidad a la luz de la transformación de nuestro sistema político y jurídico, producto de una sociedad más plural, que ha ido modificando la exigencia de un gobierno más transparente en el que no tenga cabida la impunidad como elemento determinante de la corrupción. Visto así, la eficacia de un régimen jurídico contra la corrupción en el marco de un orden jurídico constitucional, debe estar sustentada dentro de un modelo paradigmático en el que confluyan visiones complementarias que interpreten la complejidad de la sociedad actual.

Pero el debate es mucho más profundo que una eventual modificación del conjunto de normas que tratan de prevenir o sancionar la corrupción, es la definición de un proyecto nacional legitimador que garantice un cambio estructural, que se requiere de una visión de largo alcance, que mire tanto hacia fuera como hacia adentro del país, manteniendo al mismo tiempo la dinámica que beneficie a ambas trincheras. Esta definición de Estado deberá contemplarse como una transformación hacia un Estado Constitucional.

\section{II.Planteamiento de la cuestión}

En nuestro país el régimen jurídico vigente presenta una diversidad desarticulada de normas, propio de algunos sistemas de corte federal en los que no se logra un acoplamiento distributivo adecuado del orden jurídico nacional, propiciando problemas de desajuste y en algunos casos contradicción de normas. El origen de este problema obedece a varios factores, de entre los cuales destacan: las 
delimitaciones poco claras de los ámbitos de competencia entre leyes incluso de una sola instancia de gobierno, ni que decir cuando nos encontramos con facultades concurrentes, de auxilio, de interés común u otras de las causas de coordinación gubernamental.

El tema es más complejo que pensar solo en una reforma regulatoria, el problema se localiza esencialmente en el carácter ontológico; es decir, en las inconsistencias del orden jurídico desde el punto de vista teleológico y su congruencia con el entramado institucional. El Estado moderno sustenta su legitimidad en el cumplimiento de los objetivos del mismo y, para hacerlo debe contar con un cuerpo constitucional que exprese de qué manera se lograran dichos fines, de acuerdo a un proyecto en curso compartido por la sociedad.

La relación Estado-sociedad entonces, está mediada por estructuras que representan una responsabilidad mutua. Las facultades jurídicas son correlativas y su validez consiste en el apego a las obligaciones de las que surgieron de las que son correlativas. Dicho esto, de qué forma incide el fenómeno de la corrupción en la relación planteada? La respuesta implica analizar el cumplimento de facultades y obligaciones por las partes, en el entendido que es en la autoridad estatal en la que recae la potestad de crear, aplicar normas y dirimir conflictos, por lo que la corrupción se convierte en un problema estructural.

Lo anterior nos conduce a consideraciones dentro del campo de las ciencias jurídica y política, cuyo hilo conductor será la relación entre poder y derecho. Pero, para navegar en estas aguas se requiere de herramientas metodológicas y principios filosóficos consistentes y para lograrlo, es menester analizar los paradigmas que han determinado el carácter de la aprehensión de la realidad a partir de una interpretación del mundo, de acuerdo a los postulados que sustenta cada paradigma en el contexto de cada etapa en la historia de las ideas.

Thomas Khun (1922-1966) describe al "paradigma" como una visión (teoría) de la realidad, una forma de investigar y tratar los problemas, dentro de un marco teórico general, "con un conjunto de problemas definidos dentro de un marco, con 
diferentes problemas resueltos, una serie de métodos de investigación, una escala de valores $y$ un vocabulario determinado". ${ }^{3}$

\section{III.Origen y evolución del concepto Estado}

Resulta complejo establecer el origen de un concepto como el de Estado, toda vez que la evolución en las ciencias jurídicas y políticas ha tenido diferente desarrollo en el tiempo, siendo los estudiosos del ejercicio del poder los primeros en tocar la acepción desde la perspectiva de la experiencia en la acción de gobierno.

Así, el término latino status podemos encontrarlo en el siglo XIV como también en otras lenguas vernáculas como estat, stato y state usado para referirse a distintos contextos políticos. Todas estas expresiones eran utilizadas sobre todo para aludir al estado o posición de los propios gobernantes frente a los gobernados. Para finales del siglo XIV, el término status también se empleaba regularmente para hacer referencia al estado o condición de un reino o república. ${ }^{4}$

En el ámbito del derecho romano el término Estado adquiere mayor difusión. En Francia e Inglaterra en el siglo XIV se analizaba el término como el "estado del reino" o estat du roilme y aún antes, en el siglo XIII, era posible encontrarlo para referirse a magistrados, cuyo interés era el status civitatum, el estado o condición de la ciudad como entidad política independiente. Sin embargo, estos primeros usos de status fueron modificándose paulatinamente hasta adquirir de manera definitiva su significado moderno.

Esta transformación podría ser rastreada en la literatura de "espejos para príncipes", siendo la palabra stato usada para denotar la posición política de los gobernantes y para referirse al modo en que éstos debían comportarse si

${ }^{3}$ González, G. Juan Carlos, Diccionario de Filosofía, Biblioteca Edaf., Madrid España, 2000, p. 306.

${ }^{4}$ Skinner, Quentin, El Nacimiento del Estado, Editorial Gorla, Buenos Aires, 2003. www.revistapostdata.com.ar/download.php?id=10014 
deseaban mantenere lo stato ${ }^{5}$ Así llegamos a Maquiavelo, que en El Príncipe (1513) se refiere también a lo que los gobernantes debían hacer para mantener su posición política, pero asimismo se lo utilizaría por aquellos tiempos para hacer referencia a formas particulares de gobierno. ${ }^{6}$

El término Estado como concepto de los estudios en política y derecho se desarrollan desde la perspectiva de otro término, el de soberanía debiendo abordarlo en dos tendencias de la teoría constitucionalista de los siglos XV y XVI. Una de ellas sería la teoría contractualista defensora de la monarquía y la otra sería la tradición del republicanismo italiano ${ }^{7}$.Ambas tradiciones dejan de hablar de gobernantes preocupados por "mantener su estado" y comienzan a usar status o stato como el nombre de ese aparato de gobierno que nuestros gobernantes tienen la obligación de mantener y preservar.

Sería finalmente en el siglo XVII cuando teóricos legitimadores de las formas absolutistas -Bodino, Hobbes- distingan los poderes del Estado, no solo de los poderes de los gobernantes sino también de los de la comunidad.

\section{IV.La teoría contractual}

Más allá de explicar la existencia de la sociedad y el Estado, el propósito del contractualismo refiere a fundamentar una determinada concepción de la sociedad y del orden político. El contractualismo, propuesto por Hobbes (1588-1679), desarrollado por Locke (1632-1704), Rousseau (1712-1778) y Kant (1724-1804), aparece impulsado por el individualismo, la filosofía que sitúa al hombre como

\footnotetext{
${ }^{5}$ Skinner, op.cit.

${ }^{6}$ Vita, Leticia, El Concepto de Estado en la Ciencia Política Moderna. Revista Electrónica del Instituto de Investigaciones "Ambrosio L. Gioja" - Año II, Número 3. Facultad de Derecho. Universidad de Buenos Aires.

http://www.derecho.uba.ar/revistagioja/articulos/R0003A002_0004 investigacion.pdf

${ }^{7}$ Skinner, ibid
} 
realidad-fundante, presupuesto religioso, filosófico, político, social y económico del mundo. El contractualismo sirve para encontrar una nueva justificación a las relaciones sociales y políticas una vez deshecha la unidad religiosa, que había servido de elemento integrador del mundo medieval, lo que significó también el quiebre de las bases teóricas teológicas que justificaban el orden social y político. Así mismo esta corriente contractual, significó la justificación de los intereses sociales, políticos y económicos de la burguesía, clase social en acelerado proceso de consecución de un papel predominante en el desarrollo de los hechos históricos a partir del -tránsito a la modernidad. ${ }^{8}$

Se destaca que el individualismo, el racionalismo y los intereses de la burguesía convivirán sintetizados en la corriente contractualista en el transcurso de los siglos XVII y XVIII, pues esta corriente hace propicia la construcción racionalista que explica las relaciones entre el individuo, la sociedad, el Estado y la necesidad de nuevas relaciones e instituciones políticas, de acuerdo con el espíritu de esa época: -el contrato social era el único camino posible que quedaba para justificar la existencia de las instituciones sociales y políticas una vez que la razón humana se había erigido en criterio último de valores ${ }^{9}$

Estas instituciones fundamentadas en una visión contractualista deberán mantenerse fieles al principio de que la individualidad, lejos de desaparecer ante el poder de la sociedad y la autoridad del Estado, es la base de su garantía y el reconocimiento de la libertad personal y de la igualdad moral y jurídica frente a ellos. El respeto al individuo es la instancia que limita la legitimidad de actuación de los poderes públicos, de ahí que la base racionalista y abstracta del contractualismo será también una consecuencia de la ideología ilustrada y de sus precedentes en el siglo anterior.

La emancipación de América del Norte y la Revolución Francesa con sus respectivas Declaraciones de Virginia y la Declaración de Derechos del Hombre y del Ciudadano, tienen un fundamento contractualista, porque aunque dejáramos de lado el punto de vista exclusivamente formal, surge la otra modalidad del

\footnotetext{
${ }^{8}$ Fernández García, E. Teoría de la Justicia y Derechos Humanos, Madrid, 1987, p. 190.

9 Ibid p. 130.
} 
contractualismo como ideología de dominio, conservadora, que consagra el estado de cosas y fundamenta y consolida un estado de propietarios. En todo caso, estas doctrinas del pacto social, suponen la apertura de una serie de perspectivas que impulsaran en la historia a los derechos fundamentales y también a las teorías democráticas y finalmente al Estado de derecho.

La propia idea del contrato parte de la individualización de los contratantes, esta perspectiva individualista, contraria al comunitarismo y al gremialismo medieval, presupone derechos en los contratantes y la necesidad de su positivación. El contractualismo, impulsor de los derechos, concibe al Estado para garantizarlos. ${ }^{10}$

Es importante mencionar que al reformularse el contractualismo absolutista del siglo XVI y principios del XVIII, en una nueva óptica se postula que el individuo sujeto del contrato, no es ya un titular que enajena su libertad y que la somete al gobierno, sino que aparece como un titular de derechos naturales que escoge libremente y que atribuye la autoridad a los propios contratantes. Estamos ante los precedentes de la idea de soberanía popular, que actuara en la revolución liberal vinculada a la idea de Estado de derecho y derechos humanos.

El concepto de soberanía que construyó Bodino, para identificar el poder absoluto y explicar el monopolio en el uso legítimo de la fuerza, se puede construir desde el contrato como soberanía popular y como soberanía nacional. Para Rousseau la soberanía está evidentemente vinculada a su concepción del contrato social, es decir, del acto por el cual un pueblo es un pueblo.

La soberanía también puede representarse, a través de un hombre o de una asamblea de hombres, con lo que aparece la teoría de la representación que formulará Hobbes en el Leviatán y que extenderán los filósofos del siglo XVIII como Diderot, D'Holbach o Siéyes. El parlamentarismo será consecuencia de la idea de representación frente o ante la imposibilidad de la democracia directa que era la esencia del contrato social roussoniano. La soberanía deviene en principio

10 Varios: Historia de los Derechos Fundamentales. Tomo I: Tránsito a la modernidad siglos XVI y XVII, Direc.: G. Peces-Barba Martínez y otros, Dykinson, Madrid, 2001. 
de las mayorías como formación de la voluntad de los representantes, en una institución colectiva, cuya expresión política es el Parlamento. Aun así, en el siglo XVIII, esos representantes sólo pueden serlo de un sector de la población, los propietarios y las personas cultas. El sufragio para elegir a los representantes sólo les pertenecerá a ellos y los elegidos serán sólo de ese sector. La igualdad de los derechos políticos no es todavía una realidad. ${ }^{11}$

Locke ya afirmaba que el gobierno civil se basaba en el consentimiento del pueblo, en la voluntad del cuerpo político. Por tanto, la voluntad política se expresa originariamente a través del pacto que consagra los compromisos fundamentales del consentimiento y del principio de las mayorías, que es el cauce para las manifestaciones ordinarias de voluntad. Dicho consentimiento del pacto se puede identificar con la idea del poder constituyente. El consentimiento en la acción cotidiana del gobierno es el poder constituido. ${ }^{12}$

Del principio del pacto social se deduce toda la transformación de la legitimidad de origen, de la soberanía nacional y popular, del consentimiento de los gobernados y se deducen el principio de las mayorías, clave de la legitimidad de ejercicio, y también los derechos del hombre y de la construcción del concepto del Estado de derecho. ${ }^{13}$

De esta manera se puede afirmar que el hombre como ente político y realidad fundante, también es el origen del Estado, pues dicho ente político no es más que la expresión de cada individualidad quien entrega parte de su libertad y en un pacto entre todos se somete a la voluntad general representado por el Estado. La teoría se concretiza en el poder soberano del pueblo de establecer el orden político acorde con su voluntad, orden político que debiera reconocer la libertad como derecho ya existente. Pero esa libertad no es absoluta, sólo es efectiva como parte y sometida a la voluntad general del soberano. Esas limitaciones

\footnotetext{
${ }^{11}$ Varios: Historia de los Derechos Fundamentales. Tomo I op.cit

12 Ibidem

13 Cantor, Rey, Teorías políticas de la formación del Estado. Temis, $3^{a}$ ed. Bogota, 1999, p. 92. En Jorge Luis Salazar Soplapuco. Acerca del Concepto Histórico del Estado de Derecho. Revista Jurídica Cajamarca. Año IV, N 13, Octubre-Diciembre 2003.

http://www.derechoycambiosocial.com/rjc/Revista13/estado.htm
} 
impuestas a la libertad por el soberano representando a la sociedad política, se concreta en la Constitución política, dando lugar al surgimiento del Estado de derecho, pues ese Estado producto del pacto social - no puede ir más allá de los derechos que le delegan los hombres- ${ }^{14}$.

\section{El positivismo}

Una de las grandes tradiciones en investigación en las ciencias política y jurídica ha sido el positivismo lógico o neopositivismo, corriente que recibió gran influencia del Círculo de Viena, cuyos miembros al emigrar a países anglosajones generaron un gran cambio científico en el ámbito de las ciencias sociales. Esta corriente pone acento en el análisis de los procesos y mecanismos a través de los cuales los hombres interactúan políticamente, en donde la política no puede expresarse solo como poder ni como Estado, obviando un tanto los estudios institucionales, que sobre el Estado, han sido objeto de análisis de la tradición europea.

Uno de los principales exponentes del positivismo, sin duda es Kelsen quien parte de la idea de que el Estado es pura y simplemente un sistema normativo vigente. El Estado como objeto de la ciencia jurídica tiene que ser o la totalidad del orden jurídico o un orden jurídico parcial, agregando que el Estado es el orden jurídico. Como sujeto de los actos del Estado, es la personificación del orden jurídico; y como poder, no es otra cosa sino la vigencia de este orden jurídico. La crítica a esta postura dentro de las teorías modernas que superan las consideraciones formuladas por Kelsen, es en relación a lo inadmisible de identificar Estado y Derecho, ya que la realidad social, a su vez constituye la realidad estatal que crea, formula, da vida y circunscribe al Derecho a decir de Recasens Siches entre otros.

A partir de la década de los setenta surgen otras corrientes investigativas que propician un diálogo crítico respecto al neopositivismo, en el que se cuestiona el inductivismo positivista y el desconocimiento del valor de la filosofía política y de la historia en los estudios políticos, apareciendo una nueva tendencia de teóricos

${ }^{14}$ Cantor, Rey, op.cit 
que sin desconocer el valor del análisis empírico, observan la necesidad de una síntesis complementaria entre la teoría y la empiria.

Por su parte Duverger ${ }^{15}$ establece que los grupos humanos están unidos por lazos muy complejos y que sobre el concepto de Estado debe reflexionarse desde dos perspectivas; a saber: la primera, cuando se habla de la intervención del Estado en las empresas o cuando se critica al Estado o cuando se considera debe reformarse, se designa con esto al conjunto de la organización gubernamental, al conjunto de los gobernantes.

La segunda, cuando se refiere a que Francia, Italia, la Gran Bretaña son Estados, se quiere decir que ellos son comunidades humanas de un tipo particular, naciones soberanas, sin duda un parentesco visible une a los dos significados: el Estado en el primer sentido Estado-Gobierno designa al conjunto de gobernantes de una nación soberana, de un Estado en el segundo sentido Estado-Nación. En definitiva el segundo sentido es más amplio que el primero y lo engloba de alguna manera, así podemos mencionar que dentro de las formas de Estado se clasifican en: Estados Unitarios, Estados Federados y Confederación de Estados, con diversas modalidades cada uno.

\section{Estado de derecho}

El Estado de derecho marcó el inicio del Estado constitucional, en cuanto a su organización o sistema compuesto por partes conexas entre sí, para la formulación de la unidad política y jurídica. Visto así, el Estado constitucional forma parte del devenir de la historia de Occidente, el cual sustancialmente ya quedó intuido o perfilado en las proclamas favorables a los derechos humanos aun siendo al principio sólo para los respectivos ciudadanos-, en tanto se cultivó el germen de inicio para la permanente relación dialéctica entre el Estado y la sociedad, con prevalencia del ser humano como centro y eje de cualquier

${ }^{15}$ Duverger, Maurice, I sistimi politici, Editori La Terza. Roma-Bari, 1978 Tomado de Álvarez, Ángel.

www.iidh.ed.cr/comunidades/redelectoral/docs/red_diccionario/sistemas 3-04-2010 
configuración política y estatal. La autoridad, la libertad y la seguridad comenzaron a establecer un triángulo de incesante manejo y equilibrio entre sus fuerzas para la relación armónica sin subordinación, suplantación o irrespeto entre sí.

Existe la cualidad evidente del Estado constitucional como fórmula política y jurídica adentrada en las características del Estado de derecho: organización democrática del Estado y de la sociedad; elecciones periódicas con satisfacción de la libertad de votar y ser votado; existencia y respeto por los derechos humanos; distribución orgánica de funciones en tanto el poder es uno e indivisible; mecanismos administrativos y judiciales para garantizar y hacer efectivos los derechos y libertades.

El Estado constitucional presupone, entonces, la constitución aceptada y compartida en libertad y democracia, que a la vez tienen su base y protección en la constitución misma. Implica, pues, legalidad pero también legitimidad, comprende tanto la autoridad estatal como la libertad individual y social. La legitimidad del Estado constitucional no se entiende con independencia de su legalidad; no por la legalidad en sí, sino por su contenido valorativo anclado a los derechos humanos. De esa manera un Estado constitucional es legítimo en tanto su legalidad también sea legítima y no sólo válida y eficaz.

La diferencia entre legalidad y legitimidad es tan importante como la habida entre un Estado simplemente con derecho -pudiendo ser un Estado autoritario- en relación comparada al Estado de derecho; o la que se pueda encontrar entre el Estado con constitución y el Estado constitucional, el cual si bien tiene constitución formal o no, su letra o contenido se consumen en la materialidad valorativa por los derechos fundamentales.

La dinámica social produce la formación de grupos sociales, donde se agrupan los individuos que sustentan metas y objetivos comunes; los más vigorosos manifiestan la energía de las sociedades y determinan los valores sociales y políticos predominantes. La doctrina constitucional tiende a reducir esta cualidad a las propiedades del Órgano Constituyente. 
En opinión de Enrique Sánchez Bringas ${ }^{16}$,la legitimidad de una constitución no depende de la apreciación o examen de la naturaleza jurídica que la población pudiera hacer de sus normas fundamentales, sino del "querer" de un conglomerado humano o del "querer" que predomine en él. Así, la calificación de legitimidad o ilegitimidad de la constitución es resuelta por el juicio de valor que, en materia política, prevalezca en una determinada sociedad sobre el "órgano" que la expida. Ante la imposibilidad de que toda la población del Estado participe en la elaboración de la norma fundamental, es normal que se califique de "legítimo" a un congreso constituyente que manifieste la representación política de aquella.

Ahora bien, el que la autoridad sea electa es condición necesaria para la representatividad, pero no es suficiente cuando ésta resuelve sus decisiones prescindiendo total o parcialmente de las personas involucradas por ellas. La autoridad representativa no puede resolver por sí misma, su voluntad no puede ser el parámetro de sus decisiones, necesita de ciudadanos conscientes y responsables de sus derechos, capaces de reclamarlos y de apelar a la autoridad en el caso de que hayan sido vulnerados. Requiere, igualmente, de ciudadanos con presencia social, capaces de manifestar colectivamente sus ideales e intereses en los más variados ámbitos de la vida y de deliberar y negociar decisiones que articulen su voluntad con la de otros implicados.

Sin el ciudadano como interlocutor, la autoridad mal podrá accionar la naturaleza representativa que le imputa el deber ser democrático. No sólo difícil, sino imposible, será que la autoridad defienda y garantice los derechos de la gente que no los reclama; igualmente improbable será que ella articule en sus decisiones los ideales e intereses de gente que no se manifiesta. El reto es la disposición de la voluntad política para brindar igualdad de oportunidades de la participación.

\footnotetext{
${ }^{16}$ Sánchez Bringas, Enrique, Derecho Constitucional, $5^{a}$ ed.,México Ed.Porrúa,2001,pp.115123,208
} 


\section{Diferencias entre el positivismo y el postpositivismo}

En el desarrollo de las ideas en la vigencia del Estado de derecho, habría que establecer las características del paradigma positivismo -legalista-, así como las del postpositivismo como corriente que ha evolucionado del primero y que se ubica como el paradigma del Estado constitucional. Dentro del positivismo se contempla el ideal regulativo de la tipicidad, la existencia pues de normas generales y cerradas cuya aplicación no exige deliberación o valoración de normas abiertas, considerando que cualquier imperfección legal es una deficiencia de técnica legislativa cuya salida es, la delegación del órgano creador de la norma al órgano de aplicación -jueces u órganos administrativos- ${ }^{17}$

Para este paradigma, entre las normas del sistema jurídico se dan relaciones lógicas de deducibilidad. Dos normas son consistentes (lógicamente compatibles entre sí) cuando es posible cumplir ambas normas simultáneamente y al presentarse conflicto entre ellas, son de naturaleza lógica, suponiendo la imposibilidad de cumplimiento simultáneo. ${ }^{18}$ |

Por su parte el postpositivismo considera que además de las reglas, hay principios jurídicos y normas que establecen una solución normativa -dicen lo que debe ser-. Los principios así entendidos, dotan de sentido las reglas, se ven como instrumentos para le protección y promoción de ciertos bienes -valores- jurídicos. Guiar la conducta mediante principios y/o aplicar principios, al tratarse de normas abiertas, exige siempre deliberación práctica por parte de los sujetos normativos, de los destinatarios.

Entre las normas de un sistema jurídico no sólo se dan relaciones lógicas de deducibilidad. Además de a la noción lógica de consistencia normativa (posibilidad de cumplimiento simultáneo), se recurre a la idea de coherencia valorativa.

\footnotetext{
${ }^{17}$ Aguiló Regla Josef. Positivismo y Postpositivsmo. Dos Paradigmas Jurídicos En Pocas Palabras. Este texto viene a ser un resumen del Capítulo I de un libro que aparecerá en breve y que llevará por título Sobre Derecho y argumentación [Palma de Mallorca: Ed. Lleonard Muntaner, 2008]. Este trabajo ha sido realizado en el marco del proyecto de investigación SEJ 2007-64044/JURI, financiado por el Ministerio de Educación y Ciencia. DOXA, Cuadernos de Filosofía del Derecho, 30 (2007) ISSN: 0214-8676 pp. 665-675

http://www.fd.unl.pt/docentes_docs/ma/AMH_MA_11965.pdf

${ }^{18}$ Aguiló op.cit
} 
Diversas normas son valorativamente coherentes entre sí cuando presentan una unidad de sentido y/o de propósitos prácticos; y son incoherentes, cuando esa unidad no se da. A diferencia de la consistencia, que es una cuestión de todo o nada, la coherencia es una cuestión de grado. ${ }^{19}$

Desde la perspectiva de este planteamiento, existe una evolución del constitucionalismo contemporáneo en tendencia de constitucionalización del orden jurídico. Sin desconocer la crítica del planteamiento señalado dentro de la cual algunos autores apuntan sobre la condición de un retroceso del Estado de derecho, poniendo en crisis el principio de seguridad jurídica, minando así las bases sobre las que están construidos los valores de la autonomía de las personas $^{20}$.

La discusión se centra en si el cambio es de paradigma teórico, es decir reconfigurar el sistema jurídico de manera cualitativa y con ello un cambio en la teoría jurídica contemporánea ó, si la constitucionalización del orden jurídico representa una cuestión cuantitativa (de grado). Quienes están por esto último, se colocan en una posición positivista, es decir en torno a la concepción del Estado de derecho; en tanto aquellos que se inclinan por cambios cualitativos se reconocen en un campo postpositivista sustentado en el edificio del paradigma positivista.

Las reflexiones anteriores constituyen una apretada síntesis de los aspectos más representativos del paradigma postpositivista que analiza Aguiló Regla, basado en las ideas de Ricardo Guastini ${ }^{21}$.

\footnotetext{
${ }^{19}$ Ibid

${ }^{20}$ A juicio de Aguiló Regla, En España quien mejor representa desde hace ya bastantes años esta línea de crítica es Francisco Laporta, quien ha publicado recientemente un libro imprescindible sobre esta cuestión. Cfr. Laporta, 2007: El imperio de la ley. Una visión actual, Madrid: Trotta.

${ }_{21}$ Guastini,Lezioni di teoria del diritto e dello Stato, Turín: G. Giappichelli editore, , 2006,pp. 239 y ss. «En un orden jurídico no constitucionalizado —escribe Guastini- el Derecho constitucional [...] tiene un radio de acción limitado: por un lado, disciplina los aspectos fundamentales de la organización del Estado (la distribución de los poderes legislativo, ejecutivo y judicial [...]); por otro, determina los derechos de libertad de los ciudadanos frente a los poderes públicos [...] Por el contrario, en un orden constitucionalizado, el Derecho constitucional tiende a ocupar todo el espacio de la vida social y política, condicionando la legislación, la jurisprudencia, en estilo doctrinal, las acciones de los actores políticos, las relaciones privadas ...» (p. 20).
} 


\section{El modelo garantista como una propuesta del postpositivismo}

Ferrajoli ${ }^{22}$ presenta dos planteamientos, el primero como un modelo alternativo al Estado de derecho y el segundo, como una teoría del derecho que supera al iusnaturalismo y al iuspositivismo. Ambos planteamientos se identifican como: el Derecho como garantía de limitación del poder.

Grosso modo, el Estado de derecho garantista como tercer modelo del Estado de derecho, Carbonell ${ }^{23}$ es entendido como un Estado liberal mínimo y un Estado social máximo. Como teoría de derecho, éste además de la legitimación formal estricta legalidad- también tiene que satisfacer los criterios exigidos por los derechos fundamentales -legitimación sustancial-. Ferrajoli distingue a su vez derechos fundamentales de derechos humanos:

"Son derechos fundamentales todos aquellos derechos subjetivos que corresponden universalmente a 'todos' los seres humanos dotados del status de personas, de ciudadanos o personas con capacidad de obrar; entendiendo por 'derecho subjetivo' cualquier expectativa (de prestaciones) o negativa (de no sufrir lesiones) adscrita a un sujeto por una norma jurídica; y por 'status' la condición de un sujeto, prevista asimismo por una norma jurídica positiva, como presupuesto de su idoneidad para ser titular de situaciones jurídicas y/o autor de los actos que son ejercicio de éstas" ${ }^{24}$.

La propuesta de este autor incorpora en su concepción elementos como derechos subjetivos, ciudadanía, capacidad, expectativa, explicando cada una de estas acepciones en la lógica de lo que para él son los derechos fundamentales como base de la igualdad jurídica, siendo a su vez sustento de la democracia como

\footnotetext{
${ }^{22}$ Ferrajoli, Luigi,Derecho y Razón. Ed. Trotta. Madrid, 2001,Pag. 851. En Moreno Cruz Rodolfo. El modelo garantista de Luigi Ferrajoli. Lineamientos generales

${ }^{23}$ Ferrajoli, Luigi. 2005. Pasado y futuro del Estado de derecho. En Carbonell, Miguel. Neoconstitucionalismo. Ed. Trotta. Madrid, pp. 13-30.

${ }^{24}$ En realidad, aparta el concepto de derechos humanos para una función más especifica. Así establece que Derechos humanos son los derechos primarios de las personas y conciernen indistintamente a todos los seres humanos, como, por ejemplo (conforme a la constitución italiana), el derecho a la vida y a la integridad de la persona, la libertad personal, la libertad de conciencia y de manifestación del pensamiento, el derecho a la salud y a la educación y las garantías penales y procesales. Ferrajoli, L. Los fundamentos de los derechos fundamentales, Madrid, 2005: Trotta. pág. 158.
} 
legitimación sustancial. En este sentido, sostiene que la democracia tiene dos dimensiones: la democracia formal y la sustancial.

Siguiendo con Ferrajoli, en cuanto a la la dimensión formal o política constituye normas formales sobre la producción; en tanto que la dimensión sustancial son las normas sustanciales sobre la producción. Ante estas circunstancias su democracia sustancial se presenta como un concepto explicativo de las democracias constitucionales, una garantía de supervivencia de las democracias políticas y un elemento protector de los derechos fundamentales.

Toma postura respecto a dos temas primordiales de los derechos fundamentales: el concepto y su fundamento. El primero, para él, es una creación artificial y convencional y por lo tanto verificable o refutable con referencia al objeto de investigación. Pero lo segundo al ser normativo exige un proceso racional de justificación de los fines o valores éticos-políticos que aquellos sean capaces de satisfacer. ${ }^{25}$

\section{Las características de la teoría crítica ${ }^{26}$}

a) Una clara toma de conciencia del proceso que se está dando en la sociedad y, por ello, la necesidad de una crítica bajo el análisis de la racionalidad de la sociedad. Horkheimer señala los objetivos de este nuevo paradigma: "bosquejar un cuadro del proceso social con ayuda de las diversas ciencias, que lleve a un conocimiento más profundo del estado crítico del mundo y de los posibles puntos de partida para su ordenación más racional”27

\footnotetext{
25 Moreno, C. Rodolfo. Democracia y derechos fundamentales en la obra de Luigi Ferrajoli. Universitas. Revista de Filosofía, Derecho y Política. $N^{\circ} 3$. Verano 2006. http://universitas.idhbc.es/n04/04-02.pdf

${ }^{26}$ Estrada, D. Juan Antonio. 1990. La teoría crítica de Max Horkheimer. Granada. Universidad de Granada, 1990, pp. 39 y ss.

${ }^{27}$ Horkheimer, Max, Dialéctica del iluminismo. Editorial Sudamericana, Buenos Aires, 1969, p. 8. Así mismo se encuentran estas ideas en Teoría crítica. Amorrortu Editores, Buenos Aires, 1974, p. 276-283. Contreras, A. Ramiro y SÁNCHEZ, T. Guadalupe. 2007. Teoría jurídica crítica latinoamericana. Ponencia. ET/DH-1 V Congreso Europeo de latinoamericanistas, CEISAL Bruselas 2007/Abril 11-14.

http://www.reseau-amerique-latine.fr/ceisal-bruxelles/ET-DH/ET-DH-1-CONTRERAS
} 
b) Una constante referencia a la totalidad e historicidad. El mismo Horkheimer dirá que no todas las teorías son verdaderas, sino sólo las que saben captar el hecho histórico de forma profunda y la teoría crítica no es la excepción. Dos características más, encerradas en ésta, son: la de no admitir un concepto universal y objetivo de verdad y de sentirse siempre una teoría emancipadora, donde el criterio de verdad es la praxis.

Habermas $^{28}$ cita, en el texto, a Wieacker que dice: "un modelo social del derecho" representa algo así como la teoría implícita que de la sociedad tiene el sistema jurídico, es decir, la imagen que éste se hace de su entorno social".

c) Una crítica del positivismo y sus concepciones semejantes, como, por ejemplo, el empirismo metodológico del quehacer científico. ${ }^{29}$

\section{$X$. Las instituciones dentro de un régimen jurídico-político}

La apertura y consolidación de un sistema político democrático se sustenta en una base institucional amplia y eficiente garantizada por la consecución de acuerdos y por la transparencia y certidumbre en el funcionamiento de las instituciones públicas como: órganos de estado, organismos electorales, partidos políticos, etc.

En México con la consecución de cambios al sistema político, da inicio un proceso de desconcentración de poder de las fuerzas políticas, esta realidad ha tenido un impacto de gran costo en el ámbito de la función administrativa, siendo la corrupción uno de los indicadores más preocupantes para la sociedad mexicana. Si sostenemos que es la base institucional amplia y eficiente, en la que se

\footnotetext{
${ }^{28}$ Habermas, Jürgen. 1997. Faktizitaet und Geltung.. Frankufurt am Main. Suhrkamp. Citado en. Contreras, A. Ramiro y Sánchez, T. Guadalupe. 2007. Teoría Jurídica Crítica Latinoamericana. Ponencia. Et/Dh-1 V Congreso Europeo de latinoamericanistas, CEISAL Bruselas 2007/Abril 11-14. http://www.reseau-amerique-latine.fr/ceisal-bruxelles/ET-DH/ET-DH-1-CONTRERAS.pdf

29 Contreras, A. Ramiro y Sánchez, T. Guadalupe. 2007. Teoría jurídica crítica latinoamericana. Ponencia. ET/DH-1 V Congreso Europeo de latinoamericanistas, CEISAL Bruselas 2007/Abril 1114.

http://www.reseau-amerique-latine.fr/ceisal-bruxelles/ET-DH/ET-DH-1-CONTRERAS.pdf
} 
sustenta un sistema político democrático es obligado identificar, cuáles son y qué se entiende por instituciones políticas en el Estado mexicano.

Considerando su forma de gobierno, se identifican con los poderes que lo representan: Ejecutivo o Institución presidencial; Legislativo o Institución parlamentaria, y el Poder judicial o Instituciones en el ramo de procuración y administración de justicia; de igual manera, los distintos órdenes de gobierno y organismos autónomos. Es necesario reconocer que la nueva realidad política mexicana expresada a través de los grupos de poder formal y fácticos, no han sabido traducirlo en un avance efectivo dentro de un esquema de democracia sustantiva, que con visión constitucional se concibe como el constante mejoramiento de las condiciones de vida de todos los sectores de la sociedad.

Lo anterior puede analizarse en principio en dos perspectivas: una que tiene que ver con la estructura constitucional de nuestra forma de gobierno política tradicional retomada a partir de una justificación filosófica del gobierno y de una estructura institucional, presentando a las instituciones que ostentan el poder público como el ámbito per se en el que se decide el rumbo y desarrollo de un país.

La otra perspectiva, tiene que ver con la forma de encontrar los enlaces institucionales, el contenido y alcance de las políticas públicas y la manera de encontrar consensos, que permitan una definición de acuerdos respecto a un proyecto de desarrollo que sea eficaz para acortar las desigualdades sociales y evitar las distorsiones del propio sistema - entre otras la corrupción - siendo esta visión la que cobra mayor trascendencia en la actualidad.

Conviene entonces reflexionar, que la toma de decisiones es el principal elemento explicativo para entender el comportamiento en las instituciones. Éstas son vistas, analíticamente, como la consumación de opciones a través de una serie de decisiones que determinan -y a la vez están determinadas por- la estructura de la propia organización, sus relaciones jerárquicas y sus cualidades sistemáticas. 
March y Olsen $^{30}$ sostienen que todo sistema político se fundamenta en dos procesos diferentes: agregativos e integrativos. Los primeros consisten en una negociación o regateo por los cuales los grupos o individuos involucrados aceptan sacrificar algunas de sus preferencias, a cambio de satisfacer otras. Los segundos son aquellos en los que los ciudadanos participan en una dinámica de creación de preferencias compartidas por todos.

Cada una de estas visiones ofrece una perspectiva distinta de la política que a su vez se manifiesta en el régimen jurídico. Desde la perspectiva agregativa, la política se concibe como conflicto de intereses y subsecuente negociación entre ciudadanos, a partir de una dotación inicial de recursos. Desde la perspectiva integrativa, la actividad política se concibe como creación de valores y aspiraciones colectivas, que permiten la cohesión de la sociedad.

Una democracia moderna implica la convivencia de ambos procesos; el punto de partida de un proceso agregativo es el de las preferencias de los ciudadanos y su lógica operativa es el principio de racionalidad. Por su parte, los procesos integrativos son necesarios para crear sentimientos de unidad social y confianza en el sistema político. Su resultado es una cultura política, con símbolos y ritos particulares.

Plantear la idea sistémica de Easton como herramienta para estudiar el complejo mundo de los fenómenos político-jurídicos, nos permite acercarnos al concepto de sistema político y cuyos elementos están conformados por: "El régimen político, integrado por el Estado, poderes y su entramado institucional, constitución política y las leyes fundamentales reguladoras de la política, la sociedad y la economía; los actores sociales, en los que se den cabida los partidos políticos, los grupos de presión, y los movimientos sociales; la cultura política, y el escenario internacional'. ${ }^{31}$

\footnotetext{
${ }^{30}$ March, James; Olsen, Johan, El redescubrimiento de las instituciones. La base organizacional de la política. Colegio Nacional de Ciencias Políticas y Administración Pública, Universidad Autónoma de Sinaloa, Fondo de Cultura Económica. México,1997.

${ }^{31}$ Easton, David, Esquema para el análisis político. Amorrotu, Buenos Aires,1992.
} 
El autor entiende la vida política como una serie compleja de procesos, un sistema de conducta dentro de un ambiente más amplio que influye en el propio sistema político, que a su vez reacciona frente a ese estímulo. Las nociones de esta idea contemplan las interacciones políticas de la sociedad y constituyen un sistema de conducta, que es preciso verlo en los diversos ambientes que produce una sociedad, la vida política forma un sistema abierto, es decir, que no es algo cerrado, sino más bien propenso a un cambio constante de forma, que posee la capacidad de dar respuestas a las perturbaciones y en consecuencia adaptarse a las circunstancias.

G. Almond ${ }^{32}$ considera a todo sistema político como sistema de acción, en el cual se interrelacionan los elementos formales y no formales. Es un aporte reconocido de su pensamiento, la función del rol que alcanza el grado de entidad fundamental del análisis estructural-funcional y del examen por niveles: "posibilidades del sistema", "funciones de transformación", "funciones de conservación" y "adaptación". También la coacción física se valora como forma legitimante de apoyo a un orden estable, elemento propio de todo estado, y lo es, pues ella cubre un tiempo tan dilatado como es una macro etapa del desarrollo de la humanidad, cubierta por la existencia de las clases.

El análisis sistémico de la política ha servido para organizar los conceptos y presentar un esquema de análisis cualitativo más estructurado y con una terminología propia e independiente del análisis jurídico y constitucional. El uso extenso del concepto de sistema político en mucho está asociado con el nacimiento y desarrollo de la ciencia política como disciplina autónoma del derecho y de la sociología general.

Para Maurice Duverger ${ }^{33}$ de formación jurídica y constitucionalista, parte de la distinción entre instituciones, regímenes y sistemas. Por sistema social en general

\footnotetext{
${ }^{32}$ Almond, Gabriel y Coleman, James. (eds.). The politics in the developing areas, op. cit.; Gabriel A. Almond. A developmental approach to political system, World Politics, vol. 17, no. 2, January, 1965, y Gabriel A. Almond y G. B. Powell, Política comparada. Una concepción evolutiva, op. cit.

${ }^{33}$ Duverger, Maurice, op.cit
} 
entiende, en sentido laxo, todo conjunto de partes o roles en los cuales los diversos elementos forman un todo único y ordenado, siendo además éstos interdependientes entre sí. Según él, el nombre de sistema se reserva en general al conjunto de los roles o modelos de comportamiento que integran la cultura de un grupo y sirven para definirlo.

Para este pensador, el sistema político no es más que una entidad analítica para el estudio, o dicho en sus términos, es el conjunto del sistema social estudiado en sus aspectos políticos; es decir, el sistema político es el "cuadro general" en el cual "los diversos elementos se colocan en una correlación recíproca". Las instituciones políticas, a su vez, son las partes integrantes de un subsistema político denominado "régimen político". ${ }^{34}$

Respecto a nuestro país, de acuerdo a su agenda política, al análisis de una transición le debe seguir otro análisis y propuestas para su consolidación.

¿Cuáles son los requisitos necesarios para que una democracia pueda darse por consolidada? Existen dos posturas contrapuestas.

Por un lado, la restringida o minimalista, según Robert Dahl ${ }^{35}$ que identifica la consolidación con el común respeto a las mismas reglas de juego: 1) autoridades públicas electas, 2) elecciones libres y limpias, 3) sufragio universal, 4) derecho a competir por los cargos públicos, 5) libertad de expresión, 6) información alternativa y 7) libertad de asociación. No hace falta ningún otro consenso institucional o ideológico, pues basta con uno exclusivamente procedimental, reducido a la limpieza del juego electoral. En todo lo demás sobra el consenso, y los diversos actores pueden (y quizá deben, en orden al necesario pluralismo) disentir tanto en sus objetivos como en sus intereses.

Pero queda el otro punto de vista, que al requisito de consenso procedimental le añade otros adicionales en materia de legitimidad y cultura política. Esta otra perspectiva considera el respeto a las reglas de juego como una condición necesaria

\footnotetext{
${ }^{34}$ Ibid

${ }^{35}$ Dahl, Robert, La democracia y sus críticos. Paidós, Madrid, 1992.
} 
pero no suficiente, pues además del reduccionismo electoral, se requiere un cierto nivel de institucionalización democrática. Pero ¿qué clase de institucionalización?

Aquí es donde los autores divergen, pues la variedad de modelos institucionales aportada por la evidencia empírica resulta ingente, por lo que parece muy difícil generalizar proponiendo un umbral común. Además, la democracia es una experiencia en curso, abierta y cambiante, que se rehace a sí misma, estando siempre en vías de reinstitucionalización, de acuerdo a las características de cada sociedad. ${ }^{36}$ En esta línea, O'Donnell ${ }^{37}$ uno de los más reconocidos analistas de los procesos de democratización, tipifica las democracias en función de cómo esté institucionalizada la accountability. Comienza por aceptar las siete reglas minimalistas de la democracia o poliarquía propuestas por Robert Dahl, pero observa que todos ellas se refieren sólo a las instituciones electorales, dejando fuera a las demás instituciones políticas ajenas a ellas. Propone recurrir al citado concepto de accountability para incluir, dentro de su análisis, a todas las instituciones políticas, tengan o no relación directa con las elecciones.

Por accountability (responsabilidad) entiende no tanto la rendición activa de cuentas por parte del poder sino, al revés: la activa petición de cuentas que la ciudadanía le formula al poder. Distingue dos formas: la vertical, ejercida discontinuamente en cada comicio electoral, por la que cada ciudadano individual juzga retrospectivamente la ejecutoria del poder saliente, y la horizontal, ejercida constantemente, sin solución de continuidad, por la que los ciudadanos, a través de las instituciones en las que participan, controlan cotidianamente la ejecutoria de los poderes públicos, pidiéndoles cuentas si se extralimitan. ${ }^{38}$

De los temas más trascendentes en la vida de las organizaciones es el referido al poder. Para Crozier y Friedberg ${ }^{39}$ el poder no es un atributo, se da siempre en una

\footnotetext{
${ }^{36}$ Rocha, Ma. Dolores, Retos del Sistema Político Mexicano, en función de Acuerdos y Rendición de Cuentas. Ponencia. Congreso Internacional sobre la Reforma del Estado y la Administración Pública CLAD. Guatemala. Guatemala,2006.

37 O'donnell, Guillermo, Essays on Authoritarianism and Democratization. Notre Dame. IN: University of Notre Dame Press. 1999.

${ }^{38}$ O'donnell, Guillermo,Op,cit

${ }^{39}$ Crozier, M. Fiedbreg, El Actor y el Sistema. Las restricciones de la acción organizada. México, Alianza
} 
relación y, en consecuencia, se hace restrictivo a una de las partes. El concepto de poder está inseparablemente ligado a la negociación: es una relación de intercambio. Por lo tanto, en una negociación están comprometidas por lo menos dos personas. Toda relación de poder es una relación instrumental, no transitiva y recíproca, pero desequilibrada.

Es importante destacar, que estudiar el poder de las organizaciones no sólo debe circunscribirse al análisis de sus estructuras formales, toda vez que se crean zonas de incertidumbre que propician ciertas reglas y/o actores, siendo esto lo que les posibilita negociar continuamente e imponer, inclusive, su punto de vista, aún no teniendo la jerarquía pero sí la información necesaria para lograrlo, lo que constituye un esquema paralelo de ejercicio de poder.

Las instituciones, constituyen un sistema cuyo equilibrio es enjuiciado por las variaciones experimentadas en su entorno, donde las decisiones no incumben a un análisis racional, sino a una adaptación sucesiva por desequilibrios continuos que se producen. La importancia que tiene esta forma de interpretar a la organización institucional consiste en que sitúa al poder como una variable fundamental en la dinámica de los procesos organizacionales. El poder toma forma de negociaciones, gracias a las cuales se establecen los objetivos de la coalición política y se restituye el equilibrio organizativo cada vez que este es cuestionado.

Por otra parte, es necesario destacar que autores como Erhard Friedberg ${ }^{40}$ plantean el que tradicionalmente abordado tema de las organizaciones, su justificación y funcionamiento, singularizándola como un dispositivo social particular para oponerla a otras formas más difusas de acción colectiva. En este sentido suele subrayarse el carácter intencional, explícito y codificado de su orden $y$ de las estructuras, funciones, procedimientos y fines en los que descansa. Bajo el carácter formalizado de los fines, el estudio de las organizaciones se conforma como disciplina autónoma.

\footnotetext{
${ }^{40}$ Friedberg Erhard,Las cuatro dimensiones de la acción organizada; Gestión y Política Pública, Vol II, No.2, México, Julio-Diciembre de 1992, pp. 283-313.
} 
Hasta aquí hemos señalado a las organizaciones desde el punto de vista estructural y de la acción colectiva, sobre todo dentro de las organizaciones. Pero existe, además, otro tipo de consideraciones que tienen que ver con el mundo exterior a ellas, situación que Crozier y Friedberg plantean que no se puede comprender la estrategia de un actor en el seno de una organización, si no se situaba en el conjunto de los juegos en los que participaba simultáneamente, por un lado. Pero por otro, el dominio de las relaciones con segmentos del medio como una fuente de poder dentro de una organización, se ha destacado, al menos la porosidad y fluidez de las fronteras organizativas, que están determinadas por el contexto cultural en el que se desenvuelven.

\section{Reflexión en torno a los cambios en el sistema político}

Incursionar en el análisis y reflexión de nuestro sistema político-jurídico desde una visión sistémica, es condición fundamental para entender el funcionamiento de la organización institucional que de los resultados del índice de percepción de la corrupción de 2010, nuestro país obtuvo una calificación de 3.1 bajando 9 puntos con respecto al año anterior de acuerdo a Transparencia Internacional. Cada país fue calificado sobre una base de 10 y de acuerdo al resultado México se ubica en el lugar 98 de 178 lugares.

Lo anterior nos lleva a concluir que la alternancia política no vino acompañada de un cambio de las estructuras del antiguo régimen, y los intentos de reformas se hicieron dentro de las consecuencias organizacionales del mismo, pero sin el control de todas las estructuras del aparato estatal y del sistema político, las cuales permitían contar con las mayorías necesarias, al tiempo que daban certidumbre, estabilidad y legitimidad a ese proceso. Esto terminó paralizando el cambio estructural por un lado $\mathrm{y}$ ha profundizado las diferencias sociales, radicalizando a su vez las posturas políticas.

El advenimiento de la alternancia en México dejó evidencia de que la presidencia era legalmente débil ante las facultades de los otros poderes y que al final se valía 
del control de otras instituciones del sistema político para gobernar. Pero una vez desarticulado el antiguo régimen, es impensable repetir ese control.

Nos encontramos, pues, frente a la disyuntiva de una nueva realidad de la que depende el futuro de este país. Es decir, pensar en cómo configurar un régimen político-jurídico en el que las mayorías se garanticen antes de la definición de quién ejercerá el gobierno. Actualmente, primero se define quién gobernará y después se atiende cómo se lograran mayorías, situación que en los últimos períodos legislativos no se ha logrado, de lo que se colige que el actual sistema presidencialista es absolutamente disfuncional ante la nueva realidad política.

En efecto, la opacidad en las negociaciones y arreglos políticos en otros tiempos fuera de los cauces institucionales, condujo a que estas prácticas en nuestro país adquirieran mala reputación. Sin embargo debe reconocerse que en la medida que el sistema se fue abriendo, dichas prácticas permitieron las modificaciones a normas e instituciones y la edificación de un nuevo espacio público para la convivencia y competencia de la diversidad política. Hoy la negociación y acuerdo político es una necesidad que impone la realidad, ya que ésta logra disminuir las desventajas de un sistema político disfuncional. Para Giovanni Sartori" "el principal rasgo distintivo del pluralismo moderado es el gobierno de coalición". Es decir un gobierno capaz de contar con un apoyo mayoritario en el congreso.

En estos momentos, el sistema político mexicano no es una organización efectiva en lo que a gobernabilidad y combate a la corrupción se refiere, ya que convergen diversidad intereses políticos, situación que dificulta en grado extremo la eficacia de gobiernos estables a fin de garantizar un sistema integral contra la corrupción que empieza evitando la impunidad. Pero como se desprende de nuestro entramado institucional, en ello intervienen ámbitos de los diversos poderes y ordenes gubernamentales, situación que hace más complejo el proceso.

\footnotetext{
${ }^{41}$ Sartori, Giovanni,La política. Lógica y método en las ciencias sociales, FCE, 2002.
} 


\section{Consideraciones finales}

El desarrollo del concepto de Estado y del régimen jurídico que adopte desde la óptica de los paradigmas que permiten explicar sus estructuras y funcionamiento, dan cuenta del modelo prevaleciente en una sociedad determinada.

En el esfuerzo por conocer el devenir de los conceptos que dieron origen a este trabajo, es importante señalar que en ese proceso histórico del desarrollo de las ideas en torno al Estado y sus formas de ejercer el poder existe una constante, aquella que se identifica con el reconocimiento del hombre como sujeto fundante y objetivo último de la acción del Estado.

A lo largo de casi dos siglos, nuestro país se ha debatido entre la acción armada hasta la creación de instituciones que son, hoy por hoy, son cauce para los desacuerdos de una pluralidad política que representa una realidad social. Se cuenta con un sistema electoral que asume la existencia de un sistema de partidos para la competencia política, siendo la calidad política de los actores en el espacio público, en ejercicio de una ética política que garantice transparencia y compromiso social, la que definirá qué rumbo se imprime al devenir histórico.

Hemos transitado por cambios en su sistema político, viraje en curso que se encuentra asociado a una oposición cada vez más determinada a hacer valer sus posiciones de fuerza política; y una sociedad decidida a no permanecer atónita e impasible por los excesos en el ejercicio del poder.

Por lo anterior es imperativo construir condiciones de confianza y certidumbre a través de instancias existentes, a fin de promover y garantizar el acceso a una rendición de cuentas de manera eficiente. De ser así, se contribuiría a estimular la participación ciudadana para controlar, proponer cambios y ejercer derechos, situación que permitiría aumentar la calidad del desempeño institucional.

Un sistema democrático se caracteriza por la garantía que tienen los ciudadanos del reconocimiento a sus derechos y obligaciones políticas; por la eficacia del sistema electoral, así como por la existencia de una cultura ciudadana participativa 
que, hasta hoy, se destaca su análisis en un enfoque de percepción subjetiva que tiene el ciudadano respecto al poder - valores, actitudes, concepciones - y a su incidencia a la hora de elegir a sus gobernantes, de suerte que el desarrollo analítico de la participación ciudadana se ha referido principalmente respecto al interés ciudadano en los asuntos públicos, a los índices de abstencionismo, a los efectos de la mercadotecnia política, etc.

De ese enfoque de participación ciudadana da cuenta un gran número de programas de difusión para incentivarla. Sin embargo, es hora de reforzar el énfasis respecto a que la preocupación central no solo debe situarse en quienes nos gobiernan, sino con qué calidad ética y técnica lo hacen, a la hora de disponer del poder que les hemos conferido los ciudadanos, proceso que se inicia desde la regulación transparente del origen y manejo de recursos de los partidos políticos y de los asignados a los organismos encargados del arbitraje, ya que solo con la apertura y transparencia desde el ámbito del ejercicio político, pueden ser respetados nuestros derechos republicanos.

En México, fortalecer el sistema democrático requiere de una visión en dos sentidos. Por un lado, de normas jurídicas y éticas que regulen una fiscalización cuidadosa sobre los recursos públicos bajo un código de comportamiento ético. Y por el otro, de normas claras y de la eficacia en los procesos - de cualquier ámbito de los órganos de estado - cuyo incumplimiento contemple las sanciones conducentes, en el contexto de un régimen jurídico integral, coherente, en las diversas instancias de gobierno.

Hasta hoy, podemos decir que ha prevalecido una visión de índole formalista en la aplicabilidad del régimen vigente. Urge desarrollar paradigmas o modelos teóricopráctico más flexibles y descentralizados, que contemplen las nuevas complejidades de la vida social actual. En el ámbito jurídico es imperativo identificar y definir los nuevos criterios fundantes para la creación de un orden jurídico que responda a los valores prevalecientes de una sociedad plural.

Por lo anterior existe la necesidad de la generación de conocimiento jurídico que modifique la visión limitada de capacidad crítica que hasta hoy existe en los 
programas de formación del licenciado en derecho, cuya característica es su contenido descriptivo, más que investigativo respecto a lo que subyace en el fenómeno social. Solo puede existir cambio cuando se piensa de manera diferente y ese cambio se expresa en una acción cultural distinta a la prevaleciente.

\section{Bubliografía y Webgrafía}

ALMOND, Gabriel y COLEMAN, James. (eds.). The politics in the developing areas, op. cit.; Gabriel A. Almond. A developmental approach to political system, World Politics, vol. 17, no. 2, January, 1965, y Gabriel A. Almond y G. B. Powell, Política comparada. Una concepción evolutiva, op. cit.

AGUILÓ Regla Josef. Positivismo Y Postpositivsmo. Dos Paradigmas Jurídicos En Pocas Palabras. Este texto viene a ser un resumen del Capítulo I de un libro que aparecerá en breve y que llevará por título Sobre Derecho y argumentación [Palma de Mallorca: Ed. Lleonard Muntaner, 2008]. Este trabajo ha sido realizado en el marco del proyecto de investigación SEJ 2007-64044/JURI, financiado por el Ministerio de Educación y Ciencia. DOXA, Cuadernos de Filosofía del Derecho, 30 (2007) ISSN: 0214-8676 pp. 665-675

http://www.fd.unl.pt/docentes_docs/ma/AMH_MA_11965.pdf

CANTOR, Rey. Teorías políticas de la formación del Estado. Temis, $3^{a}$ ed. Bogota, 1999.p. 92. En Jorge Luis Salazar Soplapuco. Acerca del Concepto Histórico del Estado de Derecho. Revista Jurídica Cajamarca. Año IV, $\mathrm{N}^{\circ} 13$, OctubreDiciembre 2003.

http://www.derechoycambiosocial.com/rjc/Revista13/estado.htm

CROZIER, M. Fiedbreg, El Actor y el Sistema. Las restricciones de la acción organizada. México, Alianza.

DAHL, Robert.. La democracia y sus críticos. Paidós. Madrid, 1992

DUVERGER, Maurice. 1978 I sistimi politici, Editori La Terza. Roma-Bari, Tomado de Álvarez, Ángel. 04-2010

www.iidh.ed.cr/comunidades/redelectoral/docs/red_diccionario/sistemas 3-

EASTON, David.. Esquema para el análisis político. Amorrotu, Buenos Aires. 1992 
ESTRADA, D. Juan Antonio. 1990. La teoría crítica de Max Horkheimer. Granada. Universidad de Granada, 1990, pp. 39 y ss.

Fernández García, E. Teoría de la Justicia y Derechos Humanos, Madrid, 1987, p. 190

FERRAJOLI, Luigi. El fundamento de los derechos fundamentales. Madrid. Trotta, 2005.

FERRAJOLI, Luigi. Pasado y futuro del Estado de derecho. En Carbonell, Miguel. Neoconstitucionalismo. Ed. Trotta. Madrid, 2005.. Pp. 13-30.

FERRAJOLI, Luigi.. Derecho y Razón. Ed. Trotta. Madrid,2001. Pag. 851. En Moreno Cruz Rodolfo. El modelo garantista de Luigi Ferrajoli. Lineamientos generales.

FRIEDBERG Erhard, Las cuatro dimensiones de la acción organizada; Gestión y Política Pública, Vol II, No.2, México, Julio-Diciembre de 1992, pp. 283-313.

GONZÁLEZ G. Juan Carlos. Diccionario de Filosofía. Biblioteca Edaf., Madrid España, 2000,Pág. 306.

HABERMAS, Jürgen.. Faktizitaet und Geltung.. Frankufurt am Main. Suhrkamp. 1997, Citado en. CONTRERAS, A. Ramiro y SÁNCHEZ, T. Guadalupe. 2007. Teoría jurídica crítica latinoamericana. Ponencia. ET/DH-1 V Congreso Europeo de latinoamericanistas, CEISAL Bruselas 2007/Abril 11-14.

http://www.reseau-amerique-latine.fr/ceisal-bruxelles/ET-DH/ET-DH-1-

CONTRERAS.pdf

HORKHEIMER, Max.. Dialéctica del iluminismo. Editorial Sudamericana, Buenos Aires, 1969, p. 8. Así mismo se encuentran estas ideas en Teoría crítica. Amorrortu Editores, Buenos Aires, 1974, p. 276-283. CONTRERAS, A. Ramiro y SÁNCHEZ, T. Guadalupe. 2007. Teoría jurídica crítica latinoamericana. Ponencia. ET/DH-1 V Congreso Europeo de latinoamericanistas, CEISAL Bruselas 2007/Abril 11-14.

http://www.reseau-amerique-latine.fr/ceisal-bruxelles/ET-DH/ET-DH-1CONTRERAS.pdf

MARCH, James; OLSEN, Johan,El redescubrimiento de las instituciones. La base organizacional de la política. Colegio Nacional de Ciencias Políticas y Administración Pública, Universidad Autónoma de Sinaloa, Fondo de Cultura Económica. México,1997.

O'DONNELL, Guillermo. Essays on Authoritarianism and Democratization. Notre Dame. IN: University of Notre Dame Press. 1999. 
MORENO, C. Rodolfo. El modelo garantista de Luigi Ferrajoli. Lineamientos generales. Boletín Mexicano de Derecho Comparado. Nueva serie, año XL, núm, 120. Septiembre-Diciembre, 2007.pp.825-852

http://www.ejournal.unam.mx/bmd/bolmex120/BMD000012006.pdf

MORENO, C. Rodolfo. Democracia y derechos fundamentales en la obra de Luigi Ferrajoli. Universitas. Revista de Filosofía, Derecho y Política. № 3. Verano 2006. http://universitas.idhbc.es/n04/04-02.pdf

ROCHA, Ma. Dolores. Retos del Sistema Político Mexicano, en función de Acuerdos y Rendición de Cuentas. Ponencia. Congreso Internacional sobre la Reforma del Estado y la Administración Pública CLAD. Guatemala. Guatemala. 2006.

SÁNCHEZ Bringas,Enrique,Derecho Constitucional, $5^{a}$. ed., México Ed.Porrúa,2001,pp.115-123,208

SARTORI, Giovanni. 2002. La política. Lógica y método en las ciencias sociales, FCE.

SKINNER, Quentin. 2003. El Nacimiento del Estado. Editorial Gorla, Buenos Aires. www.revistapostdata.com.ar/download.php?id=10014

VARIOS: Historia de los Derechos Fundamentales. Tomo I: Tránsito a la modernidad siglos XVI y XVII, Direc.: G. Peces-Barba Martínez y otros, Dykinson, Madrid, 2001.

VITA, Leticia. 2008. El Concepto de Estado en la Ciencia Política Moderna. Revista Electrónica del Instituto de Investigaciones "Ambrosio L. Gioja" - Año II, Número 3. Facultad de Derecho. Universidad de Buenos Aires.

http://www.derecho.uba.ar/revistagioja/articulos/R0003A002_0004_investigacion.pdf 